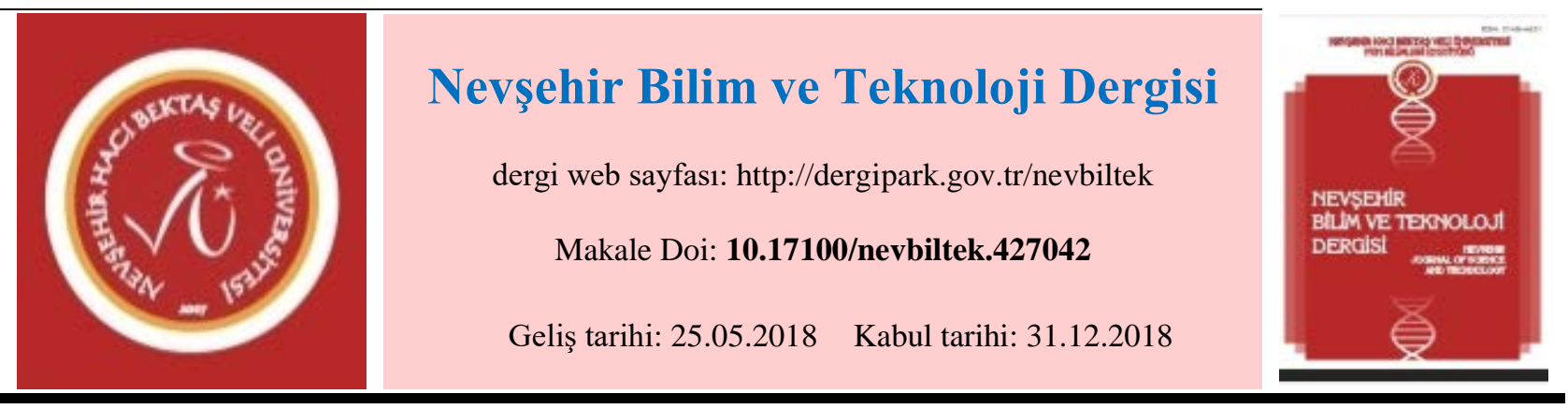

\title{
Nevşehir İli için Kızılırmak Nehri’nin İçme Suyu Potansiyelinin
}

\author{
Araştırılması \\ Seval ARAS ${ }^{1,}$, Özlem FINDIK ${ }^{2}$ \\ ${ }^{1}$ Nevşehir Hacı Bektaş Veli Üniversitesi, Mühendislik Mimarlık Fakültesi, Çevre Müh. Böl., Nevşehir \\ ORCID ID: 0000-0002-6392-0117 \\ 2Nevşehir Hacı Bektaş Veli Üniversitesi, Fen Edebiyat Fakültesi, Moleküler Biyoloji Bölümü, Nevşehir \\ ORCID ID: 0000-0001-8126-1250
}

\section{Öz}

Günümüz dünya nüfusunun artması doğal kaynaklar üzerinde istenmeyen olumsuz bir baskı yaratmaktadır. Büyüyen kentleşme ile beraber su talebinin artması, yeraltı su seviyesinin düşmesi, yapay ve doğal su kütlelerinin yetersizliğine ve su kaynaklarımızın kalitesinin düşmesine neden olmaktadır. Ülkemizdeki akarsular çoğu bölgede lağım, tarımdan gelen çok miktarda gübre, kimyasal madde, sanayi ve iş yeri kaynaklı kirli suların taşınması yoluyla alıcı ortam olarak kullanılmaktadır. İçme suyu elde etmek için kullanılan doğal su kaynaklarımız da kirletici etkisinden dolayı kalite bakımından düşmüştür. Suyun kendini temizleme sürecinde doğanın üstlenebileceği bu kirlilikler zamanla yoğunlaşmıştır.

İçme ve kullanma suyu olarak yüzeysel suların (akarsular) kullanılmasından yola çıkılarak bu çalışma ile Kızılırmak (Nevşehir İlinden geçen kısmı) Nehri'nin kullanım potansiyeli hakkında bilgi edinmek amaçlanmıştır. Kızılırmak Nehri’nden bir yıl boyunca mevsimsel olarak alınan su örneklerinde yapılan ölçümler ve analizler sonucunda amonyum 1.59 mg/l; bor $0.18 \mathrm{mg} / \mathrm{l}$ ve arsenik $0.014 \mathrm{mg} / \mathrm{l}$ ortalama değerler ile TS-266’ ya göre yüksek olarak tespit edilirken; mangan, nitrit ve sülfat TS-266 sınır değerleri arasında; nitrat, , alüminyum, krom, nikel, bakır ise TS-266 sınır değerleri altında tespit edilmiştir.

Elde edilen veriler doğrultusunda Kızılırmak Nehri’nin mevcut kirleticilere yönelik uygun arıtma tekniklerinin uygulanması ile içme ve kullanma suyu olarak kullanılabilirliği öngörülmektedir.

Anahtar Kelimeler: Kızılırmak Nehri, İçme Suyu, Su Kirliliği

\section{Assessment of Drinking Water Potential of Kızılırmak River (Nevşehir)}

\begin{abstract}
The increase of today's world population creates undesirable negative pressure on natural resources. Increasing urbanization with increased water demand and the underground water level to drop because it causes inadequacy of artificial and natural water masses and the decrease in the quality of our water resources.The rivers in Turkey are being used as discharge point for sewage, agricultural fertilizers, chemicals, industrial water. Water quality of natural water resources is falling by pollutant effects.

The aim of this study was to obtain assessment the potential of drinking water of the Kizılırmak (part of Nevsehir) River. The water samples taken from the Kizilırmak River by seasonally. The mean concentrations of ammonium (1.59 mg/l), boron (0.18 mg/l) and arsenic (0.014 mg/l) were determined higher than the limits of drinking water standards while the concentrations of nitrite, nitrate, sulphate, aluminum, chromium, nickel, copper, and manganese were determined between and lower than TS-266 limit values.

The river could be used as drinking water using appropriate treatment techniques.
\end{abstract}

Keywords: Kızılırmak River, Drinking water, Water pollution

Sorumlu yazar e-mail: saras@nevsehir.edu.tr 


\section{Giriş}

Evsel, endüstriyel ve tarımsal aktivitelerden kaynaklanan kirleticiler ilk olarak sulak alanlara karışmaktadır. Özellikle deşarj için kullanılan akarsular çevre kirliliğinden birinci derecede etkilenen ekosistemler olmuştur. Akarsular herhangi bir dış etki olmaksızın belli bir süre kendini temizleyebilme özelliği gösterebilirken; kalkınma ile beraber gelen aşırı nüfus artışı ve sanayileşme ile evsel ve endüstriyel atıklar da çoğalmış ve akarsular kendi kendini temizleyemez duruma gelmiştir [1].

Özellikle, tüm canlıların yaşamı için zorunlu ama hızla tüketilmekte olan su kaynakları bir o kadar da hızla kirletilmektedir. Endüstriyel ve evsel atık suların direk olarak alıcı ortamlara verilmesi sonucu her geçen gün sucul ortamlar kirletilmekte ve bu ortamlarda yaşayan organizmalarda olumsuz yönde etkilenmektedir. Sucul alanlara deşarj edilen atık sular içerdikleri ağır metaller, toksik bileşikler, azotlu ve karbonlu organik ve inorganik bileşikler ile bazı canlı türlerinin ölümüne, toleranslı türlerde ise fizyolojik ve morfolojik değişimlere neden olmaktadır.

Geçmişten günümüze kadar insanlar yerleşmek ve hayatlarını devam ettirebilmek için suyun en kolay elde edilebileceği bölgelere veya akarsu boylarını tercih etmişlerdir [2]. Kentleşmenin sulak bölgelerde yoğunlaşması ile artan su talebi yeraltı su seviyesini düşürmüş, yapay ve doğal su kütlelerini azaltmıştır. Akarsu ve su kütlelerinin kaynak noktalarının kentsel yerleşim bölgeleri haline gelmesi emilme ve akış sürecini olumsuz yönde etkilemiştir. Su havzalarının tarıma açılması çok miktarda kimyasal gübre ve pestisitlerin sulara girişine yol açmıştır. Su kütlelerinin azalması ile de su içerisindeki kirletici derişimi artmıştır. Böylelikle içme ve kullanma suyu elde etmek üzere arıtılarak kullanılan ham su kalitesinin düşmesine sebep olmuştur. Küresel değişimin su kalitesi ve miktarı üzerindeki etkilerinin giderek artması mevcut sorunu daha da büyütmüştür [3]. Bütün bu olumsuzluklar yerleşim yerlerinde ihtiyaç duyulan içme suyununun yetersiz kalmasina neden olmaktadır.

Geçmişte ülkemiz su kaynaklarının arıtılmasında genellikle hafif arıtım teknolojisine ağırlık verilmesi, arıtım tesislerinin yenilenememesi, bu tesislerin etkinliğinin azalmasına ve şebekeye verilen sudaki kirletici kaçakların artmasına neden olmuştur. Şebeke suyunda yüzeysel suların özellikle akarsuların kullanılmaya başlanması suyun kirlilik özelliğini değiştirmiştir. Temel su arıtımı ya da atık su arıtım uygulamaları suyu iç salgı düzenini bozan maddelerden arındıramamaktadır. İç salgı düzenini bozan maddeler yani östrojen ve androjen türevleri, deterjan parçalanma ürünlerinin yapıları kararlıdır ve kolay bozunmaya uğramazlar. İnsektisit ve bazı endüstriyel atıklar için de aynı sorun vardir [4].

Ülkemizde giderek artan su gereksinimi ve su kısıtlılı̆̆ı nedeniyle kalabalık kentlere yüzeysel suların arıtılarak verilmesi zorunluluğunun doğması suların biyolojik kirlilik ile birlikte kimyasal kirliliğinin de ön plana çıkmasına neden olmuştur. Arıtım tesislerinin büyük çoğunluğu kaliteli ham sulara göre yapılmıştır. Bu nedenle yoğun biçimde kirli sular söz konusu arıtım tesislerinin arıtma kapasitesini aşmakta, kirletici kaçakları artmaktadır. Üstelik bu kirlilik sadece yüzeysel sularla sınırlı kalmamaktadır. Yeraltı sularında ve barajlara akan sularda da önemli miktarda ağır metal kirliliği görülebilmektedir. Dünya ülkelerinin çoğunda 1 milyonu aşan insan da aynı sorunla karşı karşıyadır. Buralardaki arsenik düzeyleri EPA ya da World Health Organization (WHO) gibi kuruluşların öngördüklerinin binlerce katıdır [5-7].

Yüzeysel ve yer altı su katmanlarına sızan insan ve hayvan atıkları, çöplük şıraları, atık sular, evsel atıklar, tarımsal kimyasallar ve yeraltı depolarından olan sızıntılarla çok yüksek oranda kirlenmektedir [6-8 ve 9].

Bu bilgilerden yola çıkılarak; çalışma alanı olan Kızılırmak Nehri (Nevşehir ilinden geçen kısım) atık suların, evsel ve tarımsal kaynaklı kirleticilerin etkisi altındadır. Bu çalışma ile nehrin su kalitesinin belirlenmesi ve bölge için içme suyu olarak kullanım potansiyeli açısından değerlendirilmesi amaçlanmıştır. 


\section{Materyal ve Metot}

Kızılırmak Nehri’nin su kalitesinin belirlenmesi amacıyla Ağustos ve Kasım 2013 ile Şubat ve Mayıs 2014 tarihleri arasında Şekil 1'de gösterilen 6 istasyondan mevsimsel olarak su örnekleri toplanmıştır. Suyun çözünmüş oksijen, sıcaklık, pH ve iletkenlik değerleri Hach Lange markalı arazi tipi multi parametre ölçüm cihazı (HQ40D) ile arazi sırasında belirlenmiştir. Laboratuarda yapılacak analizler için uygun kaplara yeterli miktarlarda su örnekleri alınarak analize kadar uygun muhafaza koşullarında saklanmıştır. Örnekleme noktalarının ayrıntılı konumları Tablo1'de verilmiştir.

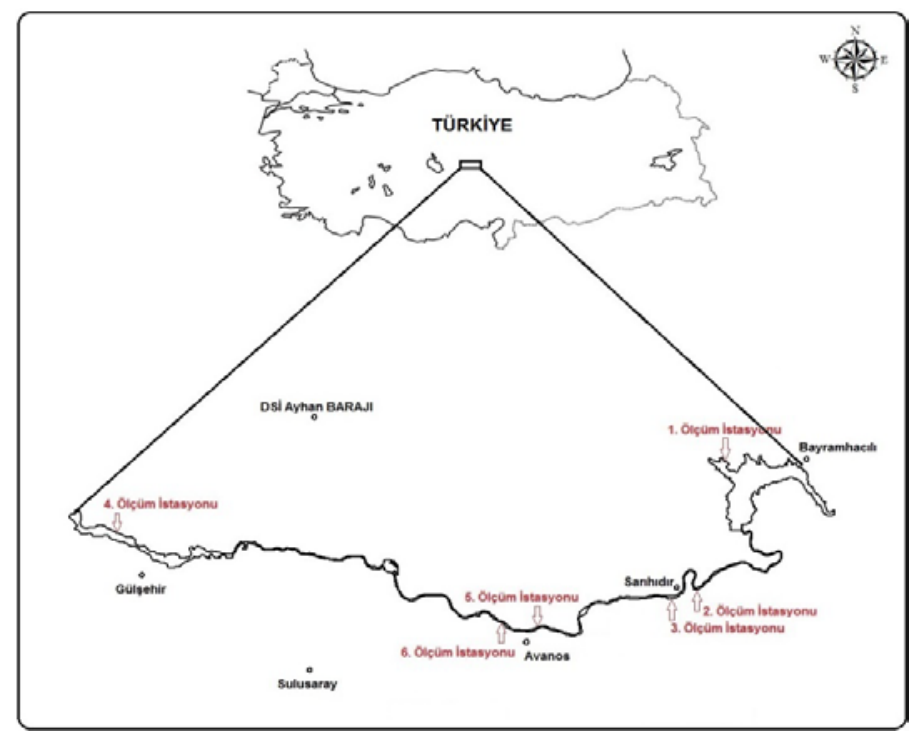

Şekil 1. Kızılırmak Nehri örnekleme noktaları

Tablo 1. Kızılırmak Nehri örnek alınan istasyonlar

\begin{tabular}{lccc}
\hline & \multicolumn{2}{c}{ Örnekleme Noktaları ve Bölgeleri } & \\
\hline 1.istasyon & Bayramhacılar Barajı’na bağlanan kol & Bayramhacılar Köyü & Kayseri \\
2.istasyon & Sarıhıdır Köyü HES yanı & Sarıhıdır Köyü & Nevşehir \\
3.istasyon & Sarıhıdır Köyü & Sarıhıdır Köyü & Nevşehir \\
4.istasyon & Gülşehir Barajı & Gülşehir & Nevşehir \\
5.istasyon & Eğlence Tesisi Önü & Avanos & Nevşehir \\
6. istasyon & Avanos arıtma tesisi çıkışı & Avanos & Nevşehir \\
\hline
\end{tabular}

\section{Laboratuar Çalışmaları}

\subsection{Fiziko-kimyasal analizler}

Arazi çalışmaları sırasında uygun kaplara alınan yeterli miktardaki su örneklerinde nitrit, nitrat, amonyum, sülfat ve Kimyasal Oksijen İhtiyacı (KOİ), fosfat seviyeleri Hach Lange markalı spektrofotometre (DR 3900) ile tespit edilmiştir. Biyolojik Oksijen İhtiyacı (BOİ) değerleri ise Velp Marka ReF. cihazı ile standart metotlar uygulanarak ölçülmüştür.

\subsubsection{Sularda element analizleri}

Laboratuara getirilen su örnekleri, çözünmüş elementlerin belirlenmesi için öncelikle, $0.45 \mu$ m gözenek çaplı membran filtreden (selüloz nitrat) süzülmüştür. Süzüntüden alınan bir miktar su numunesi (1+1) nitrik asit ile hemen $\mathrm{pH}<2$ ’ye 
ayarlanmıştır. Örneğin asit derişimi \% 1 (v/v) nitrik asite karşl1ık gelecek şekilde, uygun hacimde (1+1) nitrik asit (ör; $20 \mathrm{~mL}$ örneğe $0.4 \mathrm{~mL}(1+1) \mathrm{HNO}_{3}$ ) ilave edilmiştir. Tüp kapatılıp karıştırılarak, örnek analize hazır hale getirilmiştir [10].

Su numunelerindeki alüminyum, kurşun, kadmiyum, civa, arsenik, çinko, krom, nikel, bor, bakır, mangan, selenyum ve antimon seviyelerinin ICP-OES spektroskopik metot ile Perkin Elmer ICP-OES 7000 marka model cihazı ile ölçümleri Nevşehir Halk Sağlığı Laboratuarına hizmet alımı yolu ile yaptırılmıştır.

\section{Bulgular}

Çalışmada örnekleme noktalarından alınan su numunelerinde su kalite ve element analizleri yapılmış olup, sonuçlar Tablo 2 ve 3’te gösterilmiştir.

Tablo 2. Kızılırmak Nehir suyunun mevsimlik ortalama fiziko-kimyasal parametre değerleri

\begin{tabular}{|c|c|c|c|c|c|c|c|c|c|}
\hline \multirow{2}{*}{ Parametreler/Ort. } & \multicolumn{4}{|c|}{ Mevsimler } & \multirow{2}{*}{$\begin{array}{c}\text { TS - 266 } \\
\text { Standartlari } \\
\text { İçme ve } \\
\text { Kullanma } \\
\text { Sulari }\end{array}$} & \multicolumn{4}{|c|}{ Yüzey Sularının Kalite Özellikleri } \\
\hline & Yaz & Sonbahar & Kış & İlkbahar & & $\mathbf{I}$ & II & III & IV \\
\hline Sicaklık $\left({ }^{\circ} \mathrm{C}\right)$ & 17,8 & 11,3 & 9,2 & 15,7 & - & 25 & 25 & 30 & $>30$ \\
\hline pH & 8,12 & 8,3 & 8,9 & 9 & $6,5-9,5$ & $6,5-8,5$ & $6,5-8,5$ & $6-9$ & $\begin{array}{c}6-9 \\
\text { dişında }\end{array}$ \\
\hline İletkenlik ( $\mu \mathrm{s} / \mathrm{cm})$ & 1488 & 1528,8 & 1488,5 & 1557,5 & $650-2500$ & - & - & - & - \\
\hline ÇO (mg/l) & 9,4 & 8,8 & 10,8 & 12,2 & - & 8 & 6 & 3 & $<3$ \\
\hline BOİ (mg/l) & 12,6 & 11,3 & 10,5 & 17,5 & - & 4 & 8 & 20 & $>20$ \\
\hline KOİ (mg/l) & 8,80 & 7,80 & 13,80 & 10,30 & - & 25 & 50 & 70 & $>70$ \\
\hline Amonyum (mg/l) & 2,20 & 0,60 & 0,70 & 1,50 & $0,05-0,5$ & 0.2 & 1 & 2 & $>2$ \\
\hline Nitrit (mg/l) & 0,05 & 0,11 & 0,13 & 0,12 & $0,1-0,5$ & 0,002 & 0,01 & 0,05 & $>0,05$ \\
\hline Nitrat (mg/l) & 0,21 & 0,30 & 0,37 & 1,59 & $25-50$ & 5 & 10 & 20 & $>20$ \\
\hline Fosfat (mg/l) & 0,27 & 0,03 & 0,07 & 0,41 & - & 0,02 & 0,16 & 0,65 & $>0,65$ \\
\hline Sülfat (mg/l) & 168,80 & 179,00 & 184,10 & 185,00 & $25-250$ & 200 & 200 & 400 & $>400$ \\
\hline
\end{tabular}

Mevsimlere göre sıcaklık değişimine bakıldığında elde edilen sonuçlara göre değerler mevsim normallerinde tespit edilmiştir. Kıta içi su kalite kriterlerine göre değerlendirildiğinde ise I. Sınıf su kalitesinde olduğu tespit edilmiştir.

pH değeri; içerisinde bulunan hidrojen iyonları derişiminin negatif logaritmasıdır. pH düşüklüğü asit, yüksekliği ise baz özelliğini gösterir . Sulak alanların biyolojik ve kimyasal sistemlerinde oldukça önemli bir parametre olan pH'ın içme ve kullanma sularında olması gereken referans değeri 6,5-8,5 arasındadır [11]. Yaptığımız çalışmada ise en yüksek pH değeri ilkbahar mevsiminde $(9,0)$; en düşük değer ise yaz mevsiminde $(8,12)$ tespit edilmiştir. Değerler mevsimlere göre değişmekle beraber, Kıta içi su kalite kriterlerine göre I., II. ve III. Sınıf su kalitesinde çıkmaktadır. Kış ve ilkbahar mevsimlerinde EPA'nın belirlemiş olduğu sınır değerlerden yüksek bulunurken; TS-266'nın içme ve kullanma suyu standartlarında belirlemiş olduğu aralıkta tespit edilmiştir [10 ve 12]. İçme ve kullanma sularında iletkenlik değeri TS266'ya göre 650-2500 $\mu \mathrm{s} / \mathrm{cm}$ arasında bildirilmektedir. Çalışmada elde ettiğimiz verilere bakıldığında $1488 \mu \mathrm{s} / \mathrm{cm}$ ile $1557,5 \mu \mathrm{s} / \mathrm{cm}$ değerler ile sınır değerler arasında olduğu tespit edilmiştir [12].

Su kalitesinin belirlenmesinde önemli parametrelerden birisi sudaki çözünmüş oksijen konsantrasyonudur. İçinde çözünmüş oksijen olmayan veya az olan bir akarsu veya göl ortamı sucul canlılar için uygun olmayan bir yaşam alanı oluşturur. Sudaki çözünmüş oksijen suda yaşayan canlıların fotosentez olayı sonucu verdikleri oksijen ve atmosferden difüzyonla gelir. Oksijenin sudaki çözünürlüğü, havadaki oksijenin kimyasal basıncı, suyun sıcaklığı ve sudaki 
minerallerin derişimlerine bağlıdır. Araştırmamızda elde ettiğimiz değerlere baktığımızda kıta içi su kalite sınıflandırma kriterlerine göre I. sınıf su olarak tespit edilmiştir. Oksijen konsantrasyonundaki önemli azalmalar alıcı suda yüksek biyokimyasal oksijen ihtiyacı yaratan organik atıkların fazla miktarda suya deşarj edildiğini gösterir. Tablo 2'de verilen değerlere baktığımızda da tüm mevsimlerde BOİ ortalama değerleri kıta içi su kalite kriterlerine göre III. sınıf su kalitesinde bulunmuştur.

Organik maddelerin nitrifikasyon aşamasından geçerek tamamen zararsız hale geldiği döngünün ilk aşamasında amonyum meydana gelir. Eğer organik madde suya karıştıktan sonra nitrifikasyon tamamlanacak kadar zaman geçmemişse suda amonyum saptanır. Bunun yanında sudaki nitrit ve nitratların sudaki bakteriler ile denitrifikasyona uğraması sonucu da suda amonyum bulunabilir. Suda amonyum bulunması yakın bir noktadan suyun organik maddelerle kirletildiğini gösterir [19]. Kızılırmak nehrinde amonyum konsantrasyonu en düşük sonbahar mevsiminde 0,6 mg/l ile; en yüksek ise yaz mevsiminde $2,2 \mathrm{mg} / 1$ değerleri arasında değiş̧mektedir. Tüm mevsimlerde ölçülen ortalama değerler, TS-266'nın belirlediği sınır değer aralığından yüksek tespit edilmiştir.

Kızılırmak nehrinin nitrat değerlerine bakıldığında, nitrat konsantrasyonları TS-266, Kıta içi su kaynakları kalite kriterleri sınır değerlerinden düşük tespit edilmiştir. En yüksek ortalama nitrat değeri ilkbahar mevsiminde 1,59 mg/l bulunmuştur ve bu değer içme suyu kalite standartları açısından belirlenen sınır değerlerin altında kalmaktadır. Nitrit konsantrasyonu en düşük $0,05 \mathrm{mg} / \mathrm{l}$ ile en yüksek ise $0,13 \mathrm{mg} / \mathrm{l}$ arasında değişen değerlerde tespit edilmiştir. Mevsimsel ortalamalara baktığımızda Kıta içi su kaynakları kalite kriterleri sınır değerlerine göre yaz mevsiminde III. Sınıf kalitede, diğer mevsimlerde ise IV. Sınıf kalite su özelliği göstermektedir. TS-266'nın belirlemiş olduğu sınır değerlerin ise altında tespit edilmiştir.

Kıta içi su kaynakları kalite kriter sınır değerlerine göre; fosfat bakımından nehrin su kalite sınıfı II. ve III. Sınıf olarak belirlenmiştir. Fosfat konsantrsayonu, tüm çalışma döneminde $0,03 \mathrm{mg} / \mathrm{l}$ ile $0,41 \mathrm{mg} / \mathrm{l}$ değerleri arasında değişmektedir. Kızılırmak nehrinin metal konsantrasyon değerlerine baktığımızda bor ve arsenik metalleri dışında diğer tüm metal konsantrasyonları TS-266 standartlarındaki aralık değerlerden düşük seviyelerde tespit edilmiştir. Ayrıca tüm metaller kıta içi su kalite kriterlerinin belirlemiş olduğu sınır değerlerin altında tespit edilerek I. Sınıf su kalitesinde olduğu görülmüştür.

Tablo 3. Kızılırmak nehir suyunun mevsimsel ortalama metal konsantrasyon değerleri

\begin{tabular}{|c|c|c|c|c|c|c|c|c|c|}
\hline \multirow{3}{*}{$\begin{array}{l}\text { Metaller } \\
\text { (mg/l) }\end{array}$} & \multicolumn{4}{|c|}{ Mevsimler } & \multirow{3}{*}{$\begin{array}{c}\text { TS - } 266 \\
\text { Standartlari } \\
\text { İcme ve } \\
\text { Kullanma } \\
\text { Suları (mg/l) } \\
\end{array}$} & \multirow{2}{*}{\multicolumn{4}{|c|}{$\begin{array}{c}\text { Yüzey Sularının Kalite } \\
\text { Özellikleri } \\
\text { (mg/l) }\end{array}$}} \\
\hline & \multirow[b]{2}{*}{ Yaz } & \multirow[b]{2}{*}{ Sonbahar } & \multirow[b]{2}{*}{ Kış } & \multirow[b]{2}{*}{ İlkbahar } & & & & & \\
\hline & & & & & & I & II & III & IV \\
\hline $\mathrm{Al}$ & 0,05 & 0,019 & 0,029 & 0,004 & 0,2 & 0,3 & 0,3 & 1 & $>1$ \\
\hline $\mathrm{Zn}$ & 0,004 & 0,017 & 0,018 & 0,003 & - & 0,2 & 0,5 & 2 & $>2$ \\
\hline As & 0,013 & 0,012 & 0,013 & 0,019 & 0,01 & 0,02 & 0,05 & 0,1 & $>0,1$ \\
\hline Se & 0,001 & 0,001 & 0,001 & 0,001 & - & 0,01 & 0,01 & 0,02 & $>0,02$ \\
\hline $\mathrm{Cr}$ & 0,003 & 0,003 & 0,004 & 0,005 & 0,05 & 0,02 & 0,05 & 0,2 & $>0,2$ \\
\hline $\mathrm{Ni}$ & 0,014 & 0,009 & 0,01 & 0,013 & 0,02 & 0,02 & 0,05 & 0,2 & $>0,2$ \\
\hline B & 0,245 & 0,233 & 0,243 & - & 0,001 & 1 & 1 & 1 & $>1$ \\
\hline $\mathrm{Cu}$ & 0,01 & 0,008 & 0,006 & 0,002 & $0,1-2$ & 0,02 & 0,05 & 0,2 & $>0,2$ \\
\hline $\mathrm{Sb}$ & 0,0002 & 0,0003 & 0,0003 & 0,0005 & 0,005 & - & - & - & - \\
\hline $\mathrm{Mn}$ & - & 0,015 & 0,025 & 0,002 & $0,02-0,05$ & 0,1 & 0,5 & 3 & $>3$ \\
\hline
\end{tabular}


Çalışmada tespit edilen bor metalinin konsantrasyonuna baktığımızda mevsim değerlerinin birbirine yakın olduğu ve ortalama $0,24 \mathrm{mg} / 1$ değer ile TS-266'nın belirlediği sınır değeri geçtiği görülmüştür.

Çalışmamızda arsenik değeri mevsimsel olarak birbirine yakın belirlenmiş ancak ilkbahar en yüksek, sonbahar ise en düşük değerde tespit edilmiştir. Belirlenen ortalama $0,014 \mathrm{mg} / 1$ konsantrasyon ile TS-266'nın belirlediği sınır değeri oldukça az oranda geçtiği görülmüştür.

\section{Tartışma ve Sonuç}

Çalışmamızda elde edilen fiziko-kimyasal parametreler hem TS-266 ve yüzeysel su kalite kriterlerine göre değerlendirilmiştir.

Çalışmamızda saptanan $\mathrm{pH}$ değeri; en yüksek pH değeri ilkbahar mevsiminde $(9,0)$; en düşük değer ise yaz mevsiminde $(8,12)$ tespit edilmiştir. Yapılan diğer çalışmalarda pH değeri; Adana ve çevresindeki kaynak sularında 6,7-8,2 aralığında [14], Bursa Uludağ'daki kaynak sularında 6,8-7,4 [15], Van ve yöresindeki kaynak sularında 6,95-8,16 [16], Bursa Büyükşehir Belediyesi kaynak sularında 6,5-8,2 [17], Elazığ bölgesi kaynak sularında 7,7 [18] ve Harbiye kaynak sularında ise 7,7-8,0 [19] olarak saptanmıştır. Bu sonuçlar da bizim elde ettiğimiz sonuçlarla benzer değerlerde bulunmuştur.

Kızılırmak nehrinde amonyum konsantrasyonu en düşük sonbahar mevsiminde 0,6 mg/l ile; en yüksek ise yaz mevsiminde 2,2 mg/l değerleri arasında değişmektedir. Dönderici ve ark. [14] kaynak sularında yapmış olduğu çalı̧̧mada bakılan 55 örnekte amonyum limitinin $(0,02 \mathrm{mg} / \mathrm{l})$ altında bulunduğu, en az $0,021 \mathrm{mg} / 1$, en yüksek ise 0,087 $\mathrm{mg} / \mathrm{l}$ değerlerinin tespit edildiği ve mevzuat değerini $(0,5 \mathrm{mg} / \mathrm{l})$ geçmediği bildirilmiştir [20].

Suda bulunan amonyum, nitrit ve nitratın kaynağı gübrelerin kullanımı, sebze ve hayvanların çürümesi, evsel atıklar, kanalizasyonun toprak yüzeyine boşaltılması, endüstriyel atıklar ve çöplerin boşaltılması şeklinde olabilmektedir. Yüksek amonyum ve nitrit varlığına genellikle mikrobiyolojik bir kontaminasyonun olduğu sularda rastlanmaktadır [21].

Fosfor bileşikleri bitki nütrientleridir ve yüzey sularında alg büyümesine yol açarlar. Sudaki fosfat konsantrasyonuna bağlı olarak sulak alanlarda ötrofikasyon meydana gelebilir. Yüzey ve yeraltı sularında mevcut olan fosforun en önemli kaynaklarından biri fosfatlı gübre kullanımıdır. Hayvansal gübrenin kullanılmadan gelişi güzel bertaraf edilmesi de su kaynaklarında fosfor miktarını önemli ölçüde arttıran bir diğer faktördür. Ayrıca; evsel ve endüstriyel atıksular, insan ve hayvan dışkıları, deterjan ve temizlik maddeleri de diğer kaynaklardır. Nehrin fosfat değerlerine baktığımızda ise tespit edilen konsantrasyonlar Kıta içi su kaynakları kalite kriter sınır değerlerine göre II. ve III. Sınıf su özelliğinde olduğunu göstermektedir.

Dünya ülkeleri arasında Türkiye bor rezervinin \% 64'üne sahiptir. Borun kirletici etkisi ya içme sularına yada tarımsal alanda kullanılan sulara olan etkisinden kaynaklanmaktadır [22]. Çalışmamızda elde edilen değer yüzeysel su kalite kriteri olan $1 \mathrm{mg} / \mathrm{l}$ 'nin altında tespit edilmiştir ve I. Kalite su sınıfında olduğu belirlenmiştir [20]. Dönderici ve ark. [14] sadece bir örnekte 2,59 mg/l değerinde, diğer örneklerde ise tayin limitinin $(0,1 \mathrm{mg} / \mathrm{l})$ altında tespit edildiğini, Velioğlu ve ark. [23] Eskişehir, Balıkesir ve Kütahya'nın ilçelerine bağlı köylerden aldıkları örneklerde yalnızca Bademli Köyü suyunun bor seviyesinin ideal düzeyde olduğunu; İskele, Osmanca ve Seyitgazi’de ise değerlerin üst limiti aştığını bildirmişlerdir. 
Denizlerde ve doğal su kaynaklarında değişen seviyelerde arsenik mevcuttur. Su ısısının arttığı yerlerde arsenik oranı da artmaktadır [24]. İçme suyu kaynağı olarak kuyu suyu kullanılan iller dışında genel olarak ülkemizde arsenik yönünden herhangi bir sorun olduğu görülmemektedir. Sularında arsenik saptanan illerde ise değerler yüksek olmakla beraber izin verilen sınır değere yakın seviyelerdedir [25]. Arsenik seviyesi yönetmelikte 0,01 mg/l olarak verilmiştir [26]. Dönderici ve ark. [14] sadece bir örnekte 29,41 $\mathrm{g} / 1$ değeri ile yönetmelik değerinin aşıldığını, diğer örneklerin sınır değeri geçmediğini bildirmişlerdir. Diğer bir çalışmanın, Günşen ve ark., tarafından Bursa Uludağ'daki kaynak sularında yapıldığı ve çalışma sonucunda arsenik tespit edilmediği bildirilmiştir [15]. Bu çalışmalarla kıyaslandığında çalışmamızda saptanan değerler arasındaki farklılık sulardaki arsenik seviyelerinin çeşitliliği arazinin coğrafi yapısına, artezyen ve kuyu sularının derinliklerine ve kirletici kaynaklarının durumuna bağlı olarak değişebileceğini göstermektedir [27].

Kızılırmak nehir suyunun içme suyu olarak kullanılabilme potansiyelinin belirlenmesi amacıyla yapılan çalışmamız sonucunda su kalite kriterleri açısından çoğunlukla parametrelerin uygun olduğu tespit edilmiştir. Daha çok evsel ve tarımsal kaynaklı kirletici özellik gösteren parametrelerin (amonyum, nitrit ve fosfat) ve çalışmada yüksek bulunan As ve B metalleri göz önüne alınarak en uygun arıtma teknolojileri kullanılması ile nehrin mevcut durumunun iyileştirilmesi ve su kalite standartlarının yükseltilmesi sağlanabilir. Ayrıca ırmak kenarında eğlence amaçlı işletilen tesislerin ve piknik alanlarının kullanımının denetimi konusunda gerekli çalışmaların yapılması, çiftçi ve yöre halkının da bilinçlendirilmesi ile ırmağın bölgesel nitelikli kirlilik yükü azaltılarak zamanla I. Sınıf su kalite standartlarına ulaşması sağlanabilir.

\section{Teşekkür}

Bu çalışma; Nevşehir Hacı Bektaş Veli Üniversitesi, Bilimsel Araştırma Projeleri birimi tarafından desteklenmiştir (NEUBAP13F22 nolu proje).

\section{Kaynaklar}

[1] Dökmen F., “İhsaniye Yöresi Su Kaynaklarında Ağır Metal İçeriği ve Sulama Suyu Kullanımına Etkileri” GAP Çevre Kongresi 16-18 Ekim, Bildiri Kitabı, 1. Cilt, Şanlıurfa, 2000

[2] Alaş A., Çil O. H. Ş., “Aksaray İline İçme Suyu Sağlayan Bazı Kaynaklarda Su Kalite Paremetrelerinin İncelenmesi” Ekoloji Çevre Dergisi, 11(42), 40-44, 2002

[3] Güler Ç., “Irmak suyu ve halk sağlığı” Özgür Doruk Güler Çevre Dizisi Yazıt Yayıncılık, 43, Ankara, 2008

[4] Falconer I. R., “Are endocrine disrupting compounds a health risk in drinking water?” International Journal Environonmental Research Public Health, 3,180-184, 2006

[5] Güler Ç., “İçme suyundaki kirletici etkenler ve halk sağlı̆̆ı” Çevre ve Mühendis, 28, 89-98, 2007

[6] Güler Ç., “İçme suyundaki kirletici etkenler ve halk sağlığı” Özgür Doruk Güler Çevre Dizisi Yazıt Yayıncılık, 11, Ankara, 2008

[7] Güler Ç., Vaizoğlu S. A., “İçme suyu ham su kaynağı olarak 1rmak suyu” Hacettepe Tıp Dergisi, 39, 96-101, 2008

[8] Woodruff S. L., “Drinking water: present problems, future directions” Nutrition Clinics, 5, 1-21, 1990

[9] Haman Dorata Z., Boucher Del B., "Home water quality and safety” Florida cooperative extension service, London, University of Florida, 14M-86, 1986 
Nevşehir Bilim ve Teknoloji Dergisi (2018), 7(2) 214-222

[10] EPA Method, “Determination of Metals and Trace Elements in Water and Wastes by Inductively Coupled PlasmaAtomic Emission Spectrometry” United States Environmental Protection Agency (US-EPA), Washington, DC., EPA-821-R-01-010, 2007

[11] Soylu M., “Inland water quality management” Istanbul Technical University, Graduate School Institute of Science and Technology, M. Sc. Thesis, İstanbul, 1984

[12] Türk Standardları Enstitüsü, TS 266, “Sular-İnsani Tüketim Amaçlı Sular” 29 Nisan 2005

[13] Polat M., “Akarsu ve Göllerde İzlenen Fiziksel ve Kimyasal Parametreler” DSİ Genel Müdürlüğü Seminer Notları, Ankara, 1998

[14] Dönderici Z.S., Dönderici A., Başarı F. Kaynak Sularının Fiziksel Ve Kimyasal Kaliteleri Üzerine Bir Araştırma Türk Hijyen ve Deneysel Biyoloji Dergisi 67 (4): 167 - 172, 2010

[15] Günşen U, Anar Ş, Gündüz H. Uludağ’daki su kaynaklarının fiziksel, kimyasal ve mikrobiyolojik özellikleri. SDÜ Tıp Fakültesi Dergisi, 7(2): 21-4, 2000

[16] Ağaoğlu S, Ekici K, Alemdar S, Dede S. Van ve yöresi kaynak sularının mikrobiyolojik, fiziksel ve kimyasal kaliteleri üzerine araştırmalar. Van Tıp Dergisi,; 6(2): 30-3, 1999

[17] Sönmez S. Bursa Büyük Şehir Belediyesi içme sularının (baraj, kuyu ve kaynak) bazı kimyasal özellikleri ve mikrobiyolojik kirliliği üzerinde bir araştırma. (Alınmıştır: Alemdar S, Kahraman T, Ağaoğlu S, Alişarlı M, 2009. Bitlis ili içme sularının bazı mikrobiyolojik ve fizikokimyasal özellikleri) Uludă̆ Üniversitesi Veterinerlik Fakültesi Dergisi, 3,11: 1-9. 1992

[18] Patır B, Güven AM, Arslan A. Elazığ bölgesi içme ve kullanma, kaynak, kuyu ve göl sularının hijyenik kaliteleri üzerinde araştırmalar. Fırat Üniversitesi Sağlık Bilimleri Dergisi, 6,1-2: 127-34, 1992

[19] Tepe Y, Mutlu E. Hatay harbiye kaynak suyunun fiziko-kimyasal özellikleri. Dumlupınar Üniversitesi Fen Bilimleri Enstitüsü Dergisi, 6: 77-87. 2004

[20] Sağlık Bakanlığı Temel Sağlık Hizmetleri Genel Müdürlüğü. İnsani Tüketim Amaçlı Sular Hakkında Yönetmelik, 17 Şubat 2005 tarih, 25730 sayılı Resmi Gazete.

[21] Egemen Ö., Sunlu V., “Su Kalitesi” Ege Üniversitesi, Su Ürünleri Fakültesi Yayınlarl, 14, İzmir, 1996

[22] Doğan G, Sabah E, Erkal T. Borun çevresel etkileri üzerine Türkiye’de yapılan bilimsel araştırmalar. Türkiye 19. Uluslararası Madencilik Kongresi, 9-12 Haziran, 425-31, İzmir, 2005

[23] Velioğlu S, Şaylı B.S, Altunsoy S. Bor madeni havzalarında üretilen bazı gıdalarda bor miktarlarının belirlenmesi üzerine bir araştırma. Gıda, 24(1):13-9, 1999

[24] Yağmur F, Hancı H İ . Arsenik. STED, 11(7): 250-1, 2002

[25] Tekbaş Ö F, Oğur R. Arsenik, içme suları ve sağlık. TAF Preventive Medicine Bulletin,7(4), 2008

[26] WHO, “Arsenic in drinking-water” Background document for preparation of WHO Guidelines for drinking-water quality, Geneva, World Health Organization (WHO/SDE/ WSH/03.04/75/Rev/1), 2011

[27] Yılmaz O, Ekici K. Van yöresinde içme sularında arsenikle kirlenme düzeyler. Yüzüncü Yıl Üniversitesi Veterinerlik Fakültesi Dergisi, 15(1-2), 47-51, 2004 


\section{Extended Abstract}

\section{Introduction}

Water is a resource that has many uses, including recreational, transportation, hydroelectric power, agricultural, domestic, industrial and commercial uses. Water also supports all forms of life and affects our health, lifestyle and economic well-being. Due to the increasing water requirement and water shortage in our country, the emergence of the necessity of treatment of surface water to the crowded cities caused the pollution of the water together with the biological pollution as well as the chemical pollution. Based on this information; K1z1lirmak River (part of the province of Nevşehir) is under the influence of wastewater, domestic and agricultural pollutants. The aim of this study was to evaluate the water quality of the river and to evaluate the potential for use as drinking water for the region.

\section{Method}

The study area is located in the Nevsehir city (Fig 1). 24 water samples were collected from six stations seasonally from August 2013 to May 2014. There are six stations selected among different pollution points (sewage water, agriculture area, detergents etc.) in order to characterize the river. Water samples were collected by using sample bottles of $500 \mathrm{ml}$ for metals and $1 \mathrm{~L}$ for physicochemical parameters. The samples were stored at $+4^{\circ} \mathrm{C}$ until they were analysed. Samples were analysed for eleven physicochemical parameters: $\mathrm{PO}_{4}, \mathrm{SO}_{4}, \mathrm{NH}_{4}-\mathrm{N}, \mathrm{COD}, \mathrm{BOD}, \mathrm{NO}_{2}, \mathrm{DO}, \mathrm{NO}_{3}$, Temperature, $\mathrm{pH}$, Conductivity and ten metals: Al, Zn, As, Se, Cr, Ni, B, Cu, Sb, Mn. The water temperature, pH, conductivity and dissolved oxygen were measured with multi parameter analyser (HQ 40D) in the field. Physico-chemical parameters analyses such as nitrate, nitrite, ammonium, sulphate, phosphate, COD, BOD were carried in accordance with standard methods. Heavy metal samples were filtered immediately after transporting them to the laboratory $(0.45 \mu \mathrm{m}$ Millipore filter) and $\mathrm{HNO}_{3}$ was added to the samples until it becomes $\mathrm{pH}=2$. All metals were determined by direct aspiration of the sample solution into Perkin Elmer ICP-OES 7000 [17]. Each sample was analysed in triplicate.

\section{Results and Discussion}

The mean concentrations of physico-chemical parameters were evaluated according to TS-266 and surface water quality criteria. The highest $\mathrm{pH}$ value in spring season $(9,0)$; the lowest value was determined in summer (8.12). The ammonium concentration was $0.6 \mathrm{mg} / \mathrm{l}$ at the lowest fall season; the highest in the summer between $2.2 \mathrm{mg} / 1$ values. The phosphate values of the river, the determined concentrations are in accordance with the criteria of quality for inland water resources and it shows that the water is in the class III. The mean concentrations of ammonium (1.59 mg/l), boron $(0.18 \mathrm{mg} / \mathrm{l})$ and arsenic $(0.014 \mathrm{mg} / \mathrm{l})$ were determined higher than the limits of drinking water standards while the concentrations of nitrite, nitrate, sulphate, aluminum, chromium, nickel, copper and manganese were determined between and lower than TS-266 limit values. Boron was determined as less than $1 \mathrm{mg} / \mathrm{l}$ and it was determined to be of quality water class I. By using the most suitable treatment technologies by considering the parameters (ammonium, nitrite and phosphate) which are mostly domestic and agricultural due to the pollutant properties and the high As and B metals in the study, the current situation of the river can be improved and the water quality standards can be increased. In addition, it is possible to make the necessary studies on the use of recreational facilities and picnic areas in the river and to raise the awareness of the farmers and the local people, thus reducing the regional pollution load of the river and achieving the first class water quality standards. 